\title{
Climate Change and Sugarcane Productivity in India: An Econometric Analysis
}

\author{
*Ajay Kumar, Pritee Sharma \\ Indian Institute of Technology Indore, India \\ *a.k.seeku@gmail.com
}

\begin{abstract}
This study provides an understanding for the relationship between climatic factors and sugarcane productivity in India. The main objective of this paper is to estimates the impact of climatic and non-climatic factors on sugarcane productivity. To check the consistency of empirical results, simple linear regression model, Ricardian productivity regression (non-linear) model and Cobb-Douglas production function models are employed. The data set incorporates 390 observations corresponding to thirteen states with panel data for 30 years during 1980 to 2009. These all models include sugarcane productivity as dependent variable. Irrigated area, agriculture labour, consumption of fertilizers, literacy rate, tractors and farm harvest price (at constant level) are considered as explanatory variables. Average rainfall, average maximum and average minimum temperature include as climatic factors to capture the effect of climatic conditions on cane productivity. These climatic factors are incorporate for three weather seasons such as rainy, winter and summer. Empirical results based on Prais Winsten models with panels corrected standard errors (PCSEs) estimation shows that climatic factors i.e. actual rainfall, average maximum and average minimum temperature have a statistically significant impact on sugarcane productivity. The climatic effect for various factors on cane productivity are varies within different seasons. Average maximum temperature in summer and average minimum temperature in rainy season have a negative and statistically significant effect on sugarcane productivity. While, sugarcane productivity positively get affect with increasing average maximum temperature in rainy season and winter seasons. The study concluded that there is non-linear relationship between climatic factors and sugarcane productivity in India.
\end{abstract}

Keywords: Climate change, sugarcane productivity, India

\section{Introduction}

Sugarcane is the most important cash crop and it has an important position in the agrarian economy of India. Almost six million farmers grow sugarcane and also large numbers of agricultural laborers are engaged in cane cultivation. ${ }^{1}$ It provides the employment opportunities to more than half a million people, either skilled or semi skilled workers, mostly from rural areas. ${ }^{2}$ Approximately $7.5 \%$ rural population gets their basic livelihood resources, directly or indirectly, from sugar industries. In addition to this it also gives some fuel as a byproduct along with a large number of high-cost, value-added products (Shrivastava et al., 2011). It has a lion's share in accelerating industrialization process and bringing socioeconomic changes in rural areas (Pandey, 2007). It is the second largest agro-processing industry, costs almost Rs. 30000 crore, after textiles in India. ${ }^{3}$ The area which occupied with sugarcane is around 4.4 million hectares and an average productivity is 68 tonnes/ha. ${ }^{4}$ India is one of the major producer as well as consumer of sugar. It produces 18.9 million tonnes of sugar which is nearly $11.8 \%$ of the total sugar production of the world. 5 The sugarcane crops grow in tropical and subtropical zone in India covers 40$60 \%$ of the total cane area of the country. Preceding section is dealing with importance of sugarcane crops in India. Despite that there is limited research available in case of sugarcane productivity and climate change. Based on extensive literature review of earlier studies the authors are confirmed that productivity of major food grain and cash crops are likely to decrease with climate change (see literature review section). But in case of sugarcane crops, this is unclear whether sugarcane productivity would be increase or decrease in presence of climate change (Srivastava \& Rai, 2012).

\footnotetext{
${ }^{1}$ http://www.iisr.nic.in/iisrvision2030.pdf

${ }^{2}$ http://www.iisr.nic.in/iisrvision2030.pdf

${ }^{3}$ http://www.iisr.nic.in/iisrvision2030.pdf

${ }^{4}$ http://www.iisr.nic.in/iisrvision2030.pdf

${ }^{5}$ http://www.iisr.nic.in/iisrvision2030.pdf
} 
In this regards there are many another crucial questions which sugarcane industries and agriculture scientists have to answer like: What is influence of climatic and non-climatic variables on sugarcane productivity in India? What is the annual variation in cane productivity due to climate change? How sugarcane cane industries get affect with annual variation in cane productivity due to climate change. Thus there is a need a research for climate change and sugarcane productivity to facilitate development of appropriate farm policies. Due to this major drawback of earlier studies the present study tries to provide an understanding about climatic, non-climatic factors and sugarcane productivity in India. The main objective of this study is to assess the impact of climatic and non-climatic factors on sugarcane productivity in different weather seasons such as rainy, winter and summer seasons in India. Since sugarcane is annual crop and grows $12-18$ months in the agriculture field in India. Hence this objective would provide the scientific information that what are the influences of various climatic factors in different growing time of sugarcane crop. The importance of this study tries to assess the seasonal wise impact of climatic factors on sugarcane productivity.

\section{Literature Review}

This section of study is dealing with brief review of literature regarding climatic change and it impact of crop productivity at global and national level. Onyeji \& Fischer (1993) observed that climate change has decreased the agricultural productivity, raised food prices and declined consumer incomes. This study also reveals that climate change is declined the per capita food consumption in Egypt. Gbetibouo and Hassan (2005) study identify that agriculture is a more vulnerable sector, physically and economically due to climate change compared to other sectors of the economy. Further this study observed that climate change has drastic negative impacts in agricultural production. Bosello and Zhang (2005) study estimated the relationship between climate change and agriculture. This research shows that climate change is complex and higher temperature will influence the production patterns. Deressa et al. (2005) applied a Ricardian cross section regression model and found that sugarcane production is highly sensitive to climate change. It has a negative impact on sugar production in South Africa (Deressa et al., 2005). Masters et al. (2010) mentioned that climate change has a significant negative effect on agriculture production that occupies around $40 \%$ of the land globally.

Ramulu (1996) analyzes the impact of annual rainfall and other socio-economic factors on cane production in Andhra Pradesh. This study sown that rainfall does not have any significant impact on sugarcane crop. Ramulu (1996)'s study employed a Cobb-Douglas production function with time series data during 1973-1990. But this study did not include any other climatic variables like maximum and minimum temperature to capture the temperature effect on cane production. Srivastava \& Rai (2012) also mentioned in their review article that there is need a research to identify the climatic effect on cane productivity in India. In case of food grain crops, several studies provide the evidence that productivity of food grain crop negatively affect due to climate change such as Saseendran et al. (2000) found negative effects of temperature on rice productivity. They also mentioned that change in temperature up to $5^{\circ} \mathrm{C}$ can lead to continuous decline in rice yield and every one degree increment of temperature will lead to a $6 \%$ decline in rice yield in Kerala (India). Study by Nandhini et al. (2006) observed that cultivable land of rice is lead to decrease due to the scarcity of inputs and low rainfall in Tamil Nadu (India). Hundal \& Prabhjyot (2007) employed a simulation model and mentioned that the increase in temperature by $1^{\circ} \mathrm{C}$ lead to decrease rice and wheat yield by $3 \%$ and $10 \%$ respectively in Punjab. Kar \& Kar (2008) employed a Cobb-Douglas production function to assess the rainfall effect on jowar production in Orissa (India). This study included annual rainfall as climatic factors and concluded that low rainfall has negative impact on jowar production as well as income of the poor farmers. This study also suggested that more investment in irrigation would be useful to improved farm income in Orissa (India).

Kalra et al. (2008) undertook a state wise analysis for four states of India, namely Punjab, Haryana, Rajasthan and Uttar Pradesh. The study also concluded that wheat, mustard, barley and chickpea production has decreased due increase in seasonal temperature. Study by Kapur et al. (2009) mentioned that rainfall may decrease crops yields by $30 \%$ by the mid $21^{\text {st }}$ century. This study also justified that there would be reduction in arable land that could be results in more pressures on agriculture production In India. Kumar \& Parikh (2001) argued that the projected large-scale changes in the climate would lead to significant reductions in rice and wheat crop yields by 2060. It may affect the food security of more than one billion people in India. Haris et al. (2010) used a simulation model, mentioned that rice production may lead to decrease by $31 \%$ in 2080 due to climate change in Bihar (India). Hari et al. (2010) analyzed the climatic effects on paddy and corn crops. The analysis observed that climate change adversely affect 
the paddy and corn crop since last decade in most of the districts of Uttar Pradesh (India). Kumar et al. (2011a) concluded that climate change has shifted the weather condition which affected the seasonal crops and reduced the available growing time of rice and sugarcane crops in Uttarakhand and Uttar Pradesh (India). Geethalakshmi et al. (2011) also showed that the productivity of rice has declined by $41 \%$ with $4^{\circ} \mathrm{C}$ increase in temperature in Tamil Nadu (India).

Kumar et al. (2011b) argued that irrigated area for the production of maize, wheat and mustard in northeastern and coastal regions; rice, sorghum, and maize production in Western Ghats may decline due to climate change. Gupta et al. (2012) analyzed the climatic impact on crop productivity of rice, sorghum and millet at macro level. The authors included average temperature and actual rainfall in growing time of these crops. The empirical findings of this study showed that climate change is likely to reduce the yields of rice, sorghum and millet crop in 16 major agriculture intensive states of India. Kumar (2009) employed a Ricardian cross sectional regression model to investigate the effect of climate sensitivity on farm net revenue in India. Kumar (2009)'s study undertaken maximum temperature, minimum temperature and actual rainfall in three weather seasons like autumn, summer, rainfall and winter. The study concluded that climate change is results in 9\% reduction in agricultural farm net revenues in India. Kumar et al. (2014) investigated the impact of climatic and non-climatic factors on productivity of major food grain crops in India using a Cobb-Douglas production at state level panel data in India. In this analysis, the authors include average minimum temperature, average maximum temperature and actual rainfall as climatic factors in growing time of each crops (sowing time to harvesting time). Empirical result of the study reveals that productivity of wheat, barley, gram and rice crops are declined due to increase in actual average minimum temperature. The productivity of rice, maize, sorghum, and ragi crops are lead to decrease with increase in actual average maximum temperature in growing time of corresponding crops.

Above discussion represents that climate change is very harmful for agricultural sector. Many studies give the clear evidence that it decreased the agriculture productivity in different regions of India and other countries of the world. In India, productivity of wheat, rice, maize and other food grains crops are likely to be affected due to climate change. But in case of cane production, there are few study has been done such as Srivastava \& Rai (2012), Kumar et al. (2011a), Deressa et al. (2005), and Ramulu (1996). Hence the present study tries to fill this research gap and provide a scientific understanding about climate change and its impact on cane productivity in India. The present paper describes the empirical evidence about impact of climate change on sugarcane production. The authors employed an average maximum temperature, average minimum temperature and actual rainfall in rainy, winter and summer seasons. This investigation would be helpful to identify that which climatic factor has negative effect on sugarcane productivity in India. How various climatic factors have a seasonal influence on cane productivity in different weather seasons?

\section{Methodology}

Source and Data Description: The data set for present study is covering 30 years at state level panel data during 1980-2009. Thirteen major agricultural intensive states are taken from different agroecological zones. The states which included from tropical zone are Bihar, Orissa, Uttar Pradesh, Punjab, Haryana, Gujarat, Madhya Pradesh, West Bengal, Maharashtra and Rajasthan. Andhra Pradesh, Tamil Nadu and Karnataka are included from subtropical zone. All these states are the major food grain and cash crops (commercial crops) producers which contributes more than $75 \%$, of the total production for each crop of the country. To identify the missing values in the data set, the interpolation and graphical methods are used. The data for agricultural, socio-economic and climatic variables are taken from following sources:

1. Agricultural Data: Sugarcane production, area sown under cane cultivation, irrigated area, number of tractor, consumption of fertilizer and farm harvest price of sugarcane (at constant level 1993-94 prices) are taken from the Centre Monitoring Indian Economy (CMIE), Directorate of Economics, Statistics Ministry of Agriculture (Government of India) and Agricultural Informatics Division National Informatics Centre Ministry of Communications and IT (Government of India). Number of agricultural labors and cultivators are taken from various publication of Census (Government of India).

2. Demographic Data: Agriculture labour and state wise number of literate population in rural area is taken from various publication of Planning Commission (Government of India).

3. Climatic Variables: Minimum and maximum temperatures were obtained from the Indian Meteorological Department (IMD) (Government of India) database. This data was available on daily 
intervals with latitude and longitude $\left(0.5{ }^{\circ} \mathrm{C} \times 0.5{ }^{\circ} \mathrm{C}\right.$ grid scale $)$ information of monitoring stations. Due to the unavailability of city wise data of temperature the stations pertaining to specific latitude and longitude information were identified. Based on this information the geographical regions were identified. From the groups of such stations different geographical region were linked to arrive at the state level data points. Monthly district wise rainfall information was taken from Hydromet Division, Indian Meteorological Department (IMD, Government of India). These data were converted into city wise monthly averages and then the data transformed in to state wise. Monthly maximum temperature, minimum temperatures and rainfall for selected specific cities were collected from the 354 meteorological stations in thirteen states of India. The $\mathrm{C}^{++}$software was used to process basic information on climatic factors like rainfall, minimum temperature and maximum temperature data. The SPSS software was used to extract and bring data to excel format. Average minimum temperature and average maximum temperature and average rainfall in three weather seasons like rainy, winter and summer are incorporated for the regression analysis. Regression analysis is run by Minitab, STATA and SPSS softwares to fit the various proposed models.

Econometric Model: There are many methods are available in the existing literature to investigate the impact of climate change on agriculture productivity. These are Production function model, Ricardian cross sectional regression model, Agronomic-economic model, Agro-ecological zone model and integrated assessment model (United Nations Report, 2011). To assess the impact of climatic and socio-economic factors on sugarcane productivity, simple linear regression model, Ricardian type productivity regression (non-linear) model and Cobb-Douglas production function model are employed in the present study.

1. Simple linear regression model (LR Model): This model assumes that climatic variables are similar to other agriculture and socio-economic inputs for agriculture crop growth. This model is used by Mongi et al. (2010) to investigate the impact of climate change on agriculture production in Tanzania. Another study based on this model is undertaken by Haim et al. (2008) in Israel. Let (tp) st $_{\text {is }}$ sugarcane production in a certain time period for particular state and this is a function of several socio-economic and climatic factors. Simple linear regression model will be as-

$(t p)_{s t}=f\left\{(a s)_{s t},(i a)_{s t},(t f)_{s t},(a l)_{s t},(t t)_{s t,}(I r)_{s t},(f h p)_{s t,}(\operatorname{arfrs})_{s t},(\operatorname{arfws})_{s t},(\operatorname{arfss})_{s t},(\operatorname{amaxtrs})_{s t},(\operatorname{amaxtws})_{s t}\right.$, (amaxtss) $)_{s t}$ (amintrs) $)_{s t}$ (amintws) $)_{s t}$ (amintss) $\left.)_{t s}\right\}$

Where, $t p$ is total production for sugarcane; $s$ is cross sectional groups of states 1 to 13 ; and $t$ is the time period for 1980-2009; as is area sown under sugarcane crop (in hectare); ia is irrigated area under sugarcane crops (in hectare); $t f$ is consumption of fertilizers at planted land under sugarcane crops (in 000 tones); $a l$ is utilization of agricultural labour for cane cultivation (in numbers); $t t$ is use for tractor for cane cultivation (in numbers); $l r$ is literacy rate (in numbers) that is defined as ratio of literate rural population with gross sown area multiply by area sown under sugarcane crop; $f h p$ is the farm harvest price for sugarcane crops (in rupees at constant level 1993-94 prices); arfrs is average rainfall in rainy season (in millimeter); arfws is average rainfall in winter season (in millimeter); arfss is average rainfall in summer season (in millimeter); amaxtrs is average maximum temperature in rainy season (in degree Celsius); amaxtws is average maximum temperature in winter season (in degree Celsius); amaxtss is average maximum temperature in summer season (in degree Celsius); amintrs is average minimum temperature in rainy season (in degree Celsius); amintws is average minimum temperature in winter season (in degree Celsius); amintss is average minimum temperature in summer season (in degree Celsius). Now divide by tp to as (for production per hectare land or sugarcane productivity) and after apply simple linear regression model than equation (1) will be as-

$(t p / a s)_{s t}=\beta_{0}+\beta_{1}(\mathrm{ia})_{s t}+\beta_{2}(t \mathrm{tf})_{s t}+\beta_{3}(\mathrm{al})_{s t}+\beta_{4}(\mathrm{tt})_{s t}+\beta_{5}(\mathrm{lr})_{s t}+\beta_{6}(\mathrm{fhp})_{s t}+\beta_{7}(\mathrm{arfrs})_{s t}+\beta_{8}(\mathrm{arfws})_{s t}+\beta_{9}$ $(\text { arfss })_{s t}+\beta_{10}$ (amaxtrs) $)_{s t}+\beta_{11}$ (amaxtws) $)_{s t}+\beta_{12}$ (amaxtss) (at $+\beta_{13}$ (amintrs) (at $+\beta_{14}(\text { amintws) })_{s t}+\beta_{15}$ $(\text { amintss })_{s t}+\mu_{s t}$

Where, (tp/as) is cane productivity that is output per hectare land; $\beta_{0}$ is estimated constant coefficient and $\beta_{1}, \beta_{2}, \beta_{3}, \beta_{4}, \beta_{5}, \beta_{6}, \beta_{7}, \beta_{8}, \beta_{9}, \beta_{10}, \beta_{11}, \beta_{12}, \beta_{13}, \beta_{14}$ and $\beta_{15}$ are estimated regression coefficient for corresponding explanatory variables and $\mu_{s t}$ is an error term. Since this study is a panel data analysis and that includes sugarcane productivity as output factors and other independent variables for thirteen states for a time period, 1980-2009. So there are needed to estimate another test like state-level fixed effects that is quite beneficial in capturing unobserved heterogeneity across states. Year-specific effects model is useful to control for annual difference in sugarcane productivity for common to all states. State-by-year fixed effects model is quit beneficial to capture the unobserved heterogeneity and to control annual difference in sugarcane productivity (Gupta et al., 2012). After incorporating these variables, equation (2) will be as- 
$(\mathrm{tp} / \mathrm{as})=\beta_{0}+\beta_{1}(\mathrm{ia})+\beta_{2}(\mathrm{tf})+\beta_{3}(\mathrm{al})+\beta_{4}(\mathrm{tt})+\beta_{5}(\mathrm{Ir})+\beta_{6}(\mathrm{fhp})+\beta_{7}$ (arfrs) $+\beta_{8}$ (arfws) $+\beta_{9}$ (arfss) $+\beta_{10}$ (amaxtrs) $+\beta_{11}$ (amaxtws) $+\beta_{12}$ (amaxtss) $+\beta_{13}$ (amintrs) $+\beta_{14}$ (amintws) $+\beta_{15}$ (amintss) $)+\xi_{1(s-1)} S D_{(s-1)}+\epsilon_{1(t-}$ ${ }_{1)} T D_{(t-1)}+\psi_{1(s-1)+(t-1)} S D_{(s-1)} \times T D_{(t-1)}+\mu_{s t}$

Where, $S D_{(s-1)}$ is the vector for states dummies; $T D_{(t-1)}$ is the vector for time dummies; $\xi_{1(s-1)}$ is the estimated regression coefficient for state dummies; $€_{1(t-1)}$ is the vector of estimated regression coefficients for time dummies. In the equation (3) state dummies and time dummies are used to capture the statelevel fixed effects and to control for annual difference in sugarcane productivity to all states. $S D_{(s-1) \times T D_{(t-1)}}$ is the vector of combine states and time dummies; and $\psi_{1(s-1)+(t-1)}$ is vector of estimated regression coefficients for combine states and time dummies to state-by-year fixed effects to capture the unobserved heterogeneity and to control annual difference.

Ricardian productivity regression (non-linear regression) model (RP Model): In the present study Ricardian productivity regression (non-linear regression) model is used to estimate that whether climatic factors have a linear or non-linear relationship with sugarcane productivity. For this square root terms of each climatic factor with original terms are also added in regression analysis. Ricardian regression approach was used by many researchers to investigate the climatic impact on agricultural productivity in different region of the world like Zhai \& Zhuang (2009) in Southeast Asia; Kurukulasuriya \& Mendelsohn (2008) in Africa; Gbetibouo \& Hassan (2005) in South Africa; Mano \& Nhemachena (2007) in Zimbabwe; Seo et al. (2005) in Sri Lanka. In present study sugarcane production on per hectare land is taken as a proxy instead of net revenue on per hectare land and other explanatory variables are taken in the similar ways. Specifically Ricardian cross sectional regression approach is a quadratic formulation of climatic factors and a linear function of all other socio-economic factors (Mendelsohn et al., 1994; Kumar, 2009). We added square root terms for all climatic factors instead of quadratic term and after apply a Ricardian productivity regression model equation (3) can be written as-

$(t p / a s)_{s t}=\xi_{0}+\xi_{1}(i a)_{s t}+\xi_{2}(t f)_{s t}+\xi_{3}(a l)_{s t}+\xi_{4}(t t)_{s t}+\xi_{5}(I r)_{s t}+\xi_{6}(f h p)_{s t}+\xi_{7}(\operatorname{arfrs})_{s t}+\xi_{8}\left(\operatorname{arfrs} s^{\wedge 1 / 2}\right)_{s t}+\xi_{9}$ $(\operatorname{arfws})_{s t}+\S_{10}\left(\operatorname{arfws}^{\wedge 1 / 2}\right)_{s t}+\S_{11}(\operatorname{arfss})_{s t}+\xi_{12}\left(\operatorname{arfss}^{\wedge 1 / 2}\right)_{s t}+\xi_{13}(\operatorname{amaxtrs})_{s t}+\xi_{14}\left(\operatorname{amaxtrs^{\wedge 1/2}}\right)_{s t}+\xi_{15}$

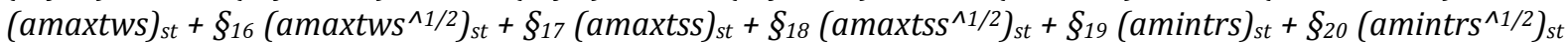
$+\xi_{21}\left(\right.$ amintws $_{s t}+\xi_{22}\left(\text { amintws }^{\wedge 1 / 2}\right)_{s t}+\oint_{23}\left(\right.$ amintss $_{s t}+\xi_{24}\left(\operatorname{amintss}^{\wedge 1 / 2}\right)_{s t}+\xi_{2(s-1)} S D_{(s-1)}+\epsilon_{2(t-1)} T D_{(t-1)}+\psi_{2(s-}$ $1)+(t-1) S D_{(s-1)} \times T D_{(t-1)}+\phi_{s t}$

Where, dependent and all explanatory variables are described in equation (1); $\S_{0}$ is estimated constant coefficient. While, $\S_{1}, \S_{2}, \S_{3}, \S_{4}, \S_{5}, \S_{6}, \S_{7}, \S_{8}, \S_{9}, \S_{10}, \S_{11}, \S_{12}, \S_{13}, \S_{14}, \S_{15}, \S_{16}, \S_{17}, \S_{18}, \S_{19}, \S_{20}, \S_{21}, \S_{22}, \S_{23}$ and $\S_{24}$ are the estimated regression coefficients for corresponding explanatory variables and $\phi_{s t}$ is an error term in the econometric model. Equation (4) is similar to Ricardian model which was applied by Mendelsohn et al. (1994) and includes climatic factors as a non-linear from and other variables as a linear form.

Cobb-Douglas production function model (C-D Model): Cobb-Douglas production function proposed by Knut Wicksell (1851-1926) and tested against statistical evidence by Cobb \& Paul (1928) in 1928 is used. ${ }^{6}$ The authors also employed a Cobb-Douglas production model to assess the impact of climate change on sugarcane productivity. This model was used by Kar and Kar (2008), Gupta et al. (2012), Kumar et al. (2014) in India; and Oduol et al. (2011) in Sub-Saharan Africa. After apply a Cobb-Douglas production function model equation (3) will take the following specification-

$\ln (t p / a s)_{s t}=\lambda_{0}+\lambda_{1} \ln (i a)_{s t}+\lambda_{2} \ln (t f)_{s t}+\lambda_{3} \ln (a l)_{s t}+\lambda_{4} \ln (t t)_{s t}+\lambda_{5} \ln (\operatorname{lr})_{s t}+\lambda_{6} \ln (f h p)_{s t}+\lambda_{7}(a r f r s)_{s t}+\lambda_{8}$

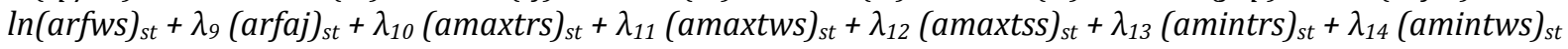
$+\lambda_{15}$ (amintss) $)_{s t}+\xi_{3(s-1)} S D_{(s-1)}+€_{3(t-1)} T D_{(t-1)}+\psi_{3(s-1)+(t-1)} S D_{(s-1)} \times T D_{(t-1)}+\xi_{s t}$

Where, $\lambda_{0}$ is estimated constant coefficient that is also known as total factor productivity (TFP) or 'Solow Residual'; $I n$ is natural logarithms; $\lambda_{1}, \lambda_{2}, \lambda_{3}, \lambda_{4}, \lambda_{5}, \lambda_{6}, \lambda_{7}, \lambda_{8}, \lambda_{9}, \lambda_{10}, \lambda_{11}, \lambda_{12}, \lambda_{13}, \lambda_{14}$ and $\lambda_{15}$ are the estimated regression coefficients for corresponding explanatory variables. These estimates are also known as estimated elasticities for respective variables under Cobb-Douglas production function model. $\xi_{s t}$ is the error term in the model. This function assumes that the production function is constant returns to scale. This is a liner production function and homogeneous degree one. Equation (4) implies the real functional form of Cobb-Douglas production function model. Similar model was used by Nastis et al. (2012) to analysis the climatic impact on agricultural productivity in Greek. Gupta et al. (2012) employed a CobbDouglas production function model to investigate the effect of climatic and non-climatic factors on rice, sorghum and millet productivity utilizing panel in India. Kumar et al. (2014) investigate the impact of climatic and non-climatic variables on productivity of major food grain crops using a Cobb-Douglas production function model in India.

6http://docentes.fe.unl.pt/ jamador/Macro/cobb-douglas.pdf 
Hypothesis Testing and Selection of Appropriate Model: In this study several regressions models are done for each proposed models to select an appropriate model. Random effects model is applied to assuming that the variation across states is to be random and uncorrelated with cane productivity. After that to capture the unobserved heterogeneity in states and to control annual difference in sugarcane productivity, fixed effects and time fixed models are used that is described in equation (3), (4) and (5) (Gupta et al. (2012), Kumar et al. (2014).

Testing for random effects: To decide either random effects or an ordinary least square regression model is appropriate or not. Breusch-Pagan Lagrange multiplier (LM) test is used for all three proposed model (Kumar et al., 2014). Null hypothesis is that variance across states is zero and it means that there is no significant difference among all states and there is no panel effect. Here we are fail to reject the null hypothesis and concluded that random effects model can be used to estimate the regression coefficient (see table 1 in appendix).

Testing for fixed or random effect: Hausman specification test is used to check the quandary of fixed and random effects model (Kumar et al., 2014). The authors tested the null hypothesis is that the preferred model is random effects and the unique error $\left(u_{i}\right)$ terms are not correlated with regressors. But Hausman $\mathrm{Chi}^{2}$ values were statistically significant at $1 \%$ level for all proposed model and null hypothesizes are rejected (see table 1 in appendix). It implies that unique error $\left(u_{i}\right)$ term significantly correlated with regressors in all proposed models. Hence fixed effects model can be considered for further regression analysis.

Testing for cross-sectional dependence/contemporaneous correlation: Cross sectional dependence is the major problem of macro level panel (over 20 years) data. If outcomes are correlated with across state then there is presence of cross sectional dependence in fixed effects model. To identify the cross sectional dependence, Breusch-Pagan Lagrange multiplier (LM) and Pesaran's (CD) test are applied for three proposed models (Kumar et al., 2014). The null hypothesis under B-P (LM) test is that the residual across states are not correlated. In this case null hypothesis is rejected. It reveals that residual across states are correlated and panel data set have a cross sectional dependency. Similar hypothesis test is used for Pesaran's (CD) test and this also shows the presence of cross sectional dependency in panel data set (see table 1 in appendix).

Testing for heteroskedasticity: Modified Wald test is applied to identify that whether heteroskedasticity exist or not (Kumar et al., 2014). The null hypothesis is that there is homoskedasticity (or constant variance). Here Modified Wald test is rejected the null hypothesis since $c h i^{2}$ values are found statistically significance at $1 \%$ level for linear, Ricardian and Cobb-Douglas production model (see table 1 in appendix). We can be concluded that there is presence of homoskedasticity in the panel data.

Testing for serial correlation: If serial auto-correlation exists in fixed effects model then outcomes are correlated across years for a given state. To address the presence the autocorrelation, Wooldridge test are used (Kumar et al., 2014). Null hypothesis is that sugarcane productivity is correlated with across year. Here null hypothesis are rejected for all proposed model since sugarcane productivity is statistically and significantly correlated with across year at $1 \%$ level (see table 1 in appendix). It implies that there is presence of serial correlation and can be concluded that panel data set have a first order auto-correlation.

Final Estimation: Finally Prais Winsten models with panels corrected standard errors (PCSEs) estimation are used for all the proposed regression models to avoid the problems of heteroskedasticity, serial correlation, auto-correlation and serial auto-correlation in fixed effects regression model (Gupta et al. (2012), Kumar et al. (2014).

\section{Results and Discussion}

The table 1 shows the empirical results for three different models; simple linear regression model (L-R model), Ricardian productivity regression model (R-P model) and Cobb-Douglas production function model (C-D model). Regression coefficients are estimated by Prais Winsten models with panels corrected standard errors (PCSEs) estimation. Empirical results show that average maximum temperature in summer and average minimum temperature in rainy season appears negative and statistically significant impact on sugarcane productivity at $1 \%$ significance level for L-R and C-D model. Sugarcane crop will get benefits with increasing maximum temperature in rainy and winter seasons. The regression coefficients 
and elasticity's of maximum temperature have a positive and statistically significant effect on cane productivity. Increasing average minimum temperature in winter and summer seasons are also found positive and statistically significant. The estimate implies a positive impact on sugarcane productivity for LR and C-D models. Average rainfall in winter seasons have a positive and statistically significant impact on sugarcane productivity. Regression coefficient of rainfall is not consistent with earlier study by Ramulu (1996). There could be one basic reason that Ramulu (1996)'s study was based only one states. Finally based on empirical findings here can be concluded that climate change through an increase in average maximum, average minimum temperature and average rainfall have significant impact on sugarcane productivity. This effect is varying within seasons for various climatic factors.

Table 1: Regression results for L-R model, R-P Model and C-D model Prais Winsten models with panels corrected standard errors (PCSEs) estimation

\begin{tabular}{|c|c|c|c|c|c|c|}
\hline $\begin{array}{l}\text { Applied } \\
\text { Model }\end{array}$ & $\begin{array}{ll}\begin{array}{l}\text { Simple Linear } \\
\text { Model }\end{array} \\
\end{array}$ & Regression & $\begin{array}{l}\text { Ricardian } \\
\text { Regression Mode }\end{array}$ & $\begin{array}{l}\text { Productivity } \\
\text { el }\end{array}$ & $\begin{array}{l}\text { C-D Production } \\
\text { Model }\end{array}$ & Function \\
\hline Variables & Reg. Coef. & Std. Error & Reg. Coef. & Std. Error & Reg. Coef. & Std. Error \\
\hline ia & $0.047910^{*}$ & 0.0080828 & $0.0240739 *$ & 0.00748 & 0.0198025 & 0.02143 \\
\hline$t f$ & $-0.16130^{* *}$ & 0.0642938 & $-0.1790186^{*}$ & 0.05431 & -0.0329882 & 0.02550 \\
\hline al & $-7.55 \mathrm{E}-08$ & $2.69 \mathrm{E}-06$ & $-7.41 \mathrm{e}-06^{*}$ & $2.01 \mathrm{E}-06$ & $-0.069963^{*}$ & 0.01760 \\
\hline$t t$ & -0.000102 & 0.0002279 & -0.0000746 & 0.000204 & -0.0160224 & 0.01835 \\
\hline lr & 4.752133* & 1.177407 & $2.310179 * * *$ & 1.323545 & $0.1410651^{*}$ & 0.0398 \\
\hline fhp & $0.017637^{* *}$ & 0.0080331 & $0.0239894 *$ & 0.007585 & $0.0752636^{*}$ & 0.01966 \\
\hline arfrs & -0.00253 & 0.0026178 & 0.0044096 & 0.007997 & -0.0264597 & 0.03340 \\
\hline $\operatorname{arfrs}^{\wedge 1 / 2}$ & NA & NA & -0.18179 & 0.470289 & NA & NA \\
\hline arfws & $0.00994^{* * *}$ & 0.00522 & $0.032026^{* *}$ & 0.013675 & 0.0342118 & 0.01594 \\
\hline $\operatorname{arfw} s^{\wedge 1 / 2}$ & NA & NA & $-0.886456^{* *}$ & 0.378393 & NA & NA \\
\hline $\operatorname{arfss}$ & 0.00500 & 0.003272 & $-0.023564^{* *}$ & 0.009823 & 0.0446389 & 0.03693 \\
\hline $\operatorname{arfss}^{\wedge 1 / 2}$ & NA & NA & $1.401276^{*}$ & 0.523348 & NA & NA \\
\hline amaxtrs & $8.129719 *$ & 0.8173265 & 133.8864* & 37.68776 & $3.59126^{*}$ & 0.77953 \\
\hline amaxtrs $\wedge^{\wedge 1 / 2}$ & NA & NA & $-1452.561^{*}$ & 433.2398 & NA & NA \\
\hline amaxtws & $1.67827^{* *}$ & 0.8066474 & $118.474^{*}$ & 24.41869 & $2.496673^{*}$ & 0.66712 \\
\hline $\operatorname{amaxtws}^{\wedge 1 / 2}$ & NA & NA & $-1248.472^{*}$ & 269.5023 & NA & NA \\
\hline amaxtss & $-7.28427^{*}$ & 1.408118 & $119.9152^{* *}$ & 48.89536 & $-4.494785^{*}$ & 1.11148 \\
\hline $\operatorname{amaxtss}^{\wedge 1 / 2}$ & NA & NA & $-1539.73^{*}$ & 592.8962 & NA & NA \\
\hline amintrs & $-4.09978^{*}$ & 0.5222698 & -0.738061 & 10.03223 & $-0.384118^{*}$ & 0.09489 \\
\hline $\operatorname{amintrs}^{\wedge 1 / 2}$ & NA & NA & 11.77637 & 106.0642 & NA & NA \\
\hline amintws & $1.81255^{*}$ & 0.6318183 & $14.82338^{* *}$ & 5.755262 & 0.039280 & 0.22209 \\
\hline $\operatorname{amintws}^{\wedge 1 / 2}$ & NA & NA & $-101.4968^{* *}$ & 47.51834 & NA & NA \\
\hline amintss & $1.37561^{*}$ & 0.377451 & 16.25332 & 15.59702 & $0.5075401^{*}$ & 0.18114 \\
\hline $\operatorname{amintss}^{\wedge 1 / 2}$ & NA & NA & 175.4554 & 144.979 & NA & NA \\
\hline con. coef. & 36.2764 & 46.64806 & 11949.32* & 2048.546 & -0.3297855 & 1.56667 \\
\hline
\end{tabular}

Source: Estimated by Authors and ${ }^{*}, * *$ and ${ }^{* * *}$ indicates the $1 \%, 5 \%$ and $10 \%$ significance level for respective variables. $\mathrm{NA}=$ No data.

In case of non-climatic variables irrigation is found an important to increase the cane productivity. Because irrigated area has a positive and statistically significant influence on cane productivity under LR model. The elasticity of irrigated area with sugarcane productivity is also positive but statistically insignificant under C-D model. Here can be justified that additional irrigation facilities could be a crucial option to mitigate the adverse effect of climate change on cane productivity. Increasing application of fertilizers in cane cultivation would be harmful. The estimated regression coefficient of fertilizers has a negative and statistically significant impact on cane productivity under simple linear regression model. Another harmful effect of more fertilizers application would be caused in greater climatic and environmental damage (Ranuzzi \& Srivastava, 2012). The elasticity of agriculture labour with cane productivity shows that the negative and statistically significant association. Estimate implies that more utilization of agriculture labour in cane cultivation would be caused in decline cane productivity. More specifically, more utilization of human power may not be useful to improve the marginal productivity of land. 
The participation of literate population in cane cultivation is found a significant variable to increase cane productivity. Our estimates i.e. the elasticity and regression coefficient of literate population has a positive and statistically significant impact on cane productivity. There could be one major reason that literate farmer has a more understanding compared to illiterate. Literate farmers can chose an appropriate crop for cultivation. They are more aware for suitable sowing time of crops, irrigation time. They have more understanding that how much fertilizer and pesticides have to use in cane cultivation. Another important thing is that they are able to select adaptation methods to mitigate the adverse effects of climate change. Cane productivity negatively affect with the use of tractor. Although the regression coefficient and elasticity of tractor with cane productivity are statistically in-significant. Therefore negative sign for both show the negative effect on cane productivity. The estimates imply that mechanization may not be useful to increase the cane productivity. There could be many scientific reasons: 1) in India most of farmers are small and marginal, 2) the average size of smallholder farming system is $(<2.0$ hectare per farm $)$ that accounts for $78 \%$ of the total operational holdings, 3$)$ this operational holdings occupies $32 \%$ of total agricultural area and the average size of 84 million small farm holdings is $(<1$ hectare per farm). Due to small sizes of farm holding, marginal productivity of land would lead to decrease with increase in mechanization. Appropriate price of crop could be caused to increase the productivity of sugarcane. Our estimated regression coefficient and elasticity of farm harvest price with cane productivity are found positive and statistically significant. There could be one crucial reason is that farmer give the preference to those crops which may provide the more financial benefits. It would increase the decision power of farmers to select an appropriate crop for cultivation. More specifically, it would provide the motivation to farmers for sugarcane cultivation. They will give more preference to crop cultivation and productivity would be increased. All regression coefficients for original terms of climatic factors and square root terms of climatic factors have an opposite sign. These estimates reveal show that climatic factors have a non-linear relationship with sugarcane productivity.

\section{Conclusion and Recommendations}

The main aim of this study is to assess the impact of climatic and non-climatic on sugarcane productivity in different weather season. Sugarcane productivity as dependent variables and other climatic and nonclimatic factors as explanatory variables are compiled a panel data set for thirteen states during 19802009. To check the consistency of empirical results, simple linear regression model (L-R model), Ricardian productivity regression (non-linear) model (R-P model) and Cobb-Douglas production function model (C-D model) are employed. Regression results based on Prais Winsten models with panels corrected standard errors (PCSEs) estimations show that average maximum temperature and average minimum temperature in summer and rainy season are appears negative and statistically significant impact on sugarcane productivity. While, sugarcane crop will get benefits with increasing average maximum temperature in rainy and winter seasons. Rising average minimum temperature in winter and summer seasons are found positive and statistically significant influence on sugarcane productivity. Sugarcane productivity would be improved with increase in average rainfall in winter seasons. These estimates imply that climate change, through increase in average maximum temperature and average minimum temperature and changing rainfall pattern have a statistically significant effect on sugarcane productivity in different weather seasons in India. Finally this study provides the empirical evidence that climatic factors have a non-linear relationship with sugarcane productivity.

In brief our estimation shows that climatic factors have negative influence on sugarcane productivity. Thus it would be a serious threat for most of the marginal and substantial farmers those are engaged in sugarcane cultivation for their livelihood and agricultural labour and industry based on sugarcane in India. Hence the study tries to provide an understanding to Indian policy makers toward the sugarcane farm policies in presence of climate change. This study also provides a several policy suggestions like Indian policy maker is need to provide more irrigation facilities for cane cultivation. Our results show that irrigation has positive and statistical significant influence on sugarcane productivity. Another important suggestion is that policy makers should provide appropriate price to farmers for their agriculture production. Our empirical findings also shows that farm harvest price of sugarcane crops are very crucial thing to improve the productivity of sugarcane crop. There would be one significant reason that farmers give preference to those crops which will provide more financial benefits. Appropriate price of crops will also increase the decision power of farmers to select a more financially beneficial crop for cultivation.

Acknowledgements- This paper has been presented at $7^{\text {th }}$ Biennial Conference of Indian Society for Ecological Economics (INSEE) on Global Change, Ecosystems, Sustainability, December 04-08, 2013, 
Tezpur University, Tezpur (Assam). The authors are grateful to Professor Jagdish Krishnaswami (Session Chair in my paper presentation in this Conference), and Dr. Amarnath Tripathi (Assistant Professor, Institute of Economic Growth, Delhi) for giving their valuable suggestions and comments in this paper. Authors also would like to give thanks to conference participants to giving their helpful comments in this paper.

\section{References}

Bosello, F. \& Zhang, J. (2005). Assessing Climate Change Impacts: Agriculture. CIP-Climate Impacts and Policy Division Working Paper 02 Available at: http://www.eclac.cl/ilpes/noticias/paginas/1/35691/Bosello_assesingclimatechangeimpacts.pd f.

Cobb, C. W. \& Douglas, P. H. (1928). A Theory of Production. American Economic Review, 18(1), 139-156.

Deressa, T., Hassan, R. \& Poonyth, D. (2005). Measuring the Impact of Climate Change on South African Agriculture: The Case of Sugarcane Growing Regions. Agrekon, 44(4), 524-542.

Gbetibouo, G. A. \& Hassan, R. M. (2005). Measuring the Economic Impact of Climate Change on Major South African Field Crops: A Ricardian Approach. Global and Planetary Change, 47, 143-152.

Gupta, S., Sen, P. \& Srinivasan, S. (2012). Impact of Climate Change on Indian Economy: Evidence from Food Grain Yields. Centre for Development Economics Working Paper 218, Delhi.

Geethalakshmi, V., Lakshmanan, A., Rajalakshmi, D., Jagannathan, R., Sridhar, G., Ramara, Bhuvaneswari, A. P., Gurusamy, K. L. \& Anbhazhagan, R. (2011). Climate Change Impact Assessment and Adaptation Strategies to Sustain Rice Production in Cauvery Basin of Tamil Nadu. Current Science, 101(03). 342-347.

Haris, A. A., Biswas, S. \& Chhabra, V. (2010). Climate Change Impacts on Productivity of Rice (Oryza Sativa) in Bihar. Indian Journal of Agronomy, 55(4), 295-298.

Haim, D., Shechter, M. \& Berliner, P. (2008). Assessing the Impact of Climate Change on Representative Field Crops in Israeli Agriculture: A Cause Study of Wheat and Cotton. Climatic Change, 86,425440.

Hari, B. D., Gernot, B., Charity, G. O. \& Hemanta, K. T. (2010). Capitalizing on Assets: Vulnerability and Adaption to Climate Change in Nepal. Social Development Papers Social Dimensions of Climate Change Paper, 121.

Hundal, S. S. \& Prabhjyot, K. (2007). Climate Variability and its Impact on Cereal Productivity in Punjab India. Current Science, 92(04), 506-512.

Kumar, A., Sharma, P. \& Ambrammal, S. K. (2014). Climatic Effects on Food Grain Productivity in India: A Crop Wise Analysis. Journal of Studies in Dynamics and Change, 1(1), 38-48.

Kumar, K. S. K. \& Parikh, J. (2001). Socio-economic Impacts of Climate Change on Indian Agriculture. International Review for Environmental Strategies, 2(2), 277-293.

Kumar, K. S. K. (2009). Climate Sensitivity of Indian Agriculture does Spatial Effects Matter. SANDEE Working Paper 45-09, Kathmandu.

Kumar, V., Sharma, Y. \& Chauhan, S. (2011a). Impact of Climate Change on the Growth and Production of Saccharum Offcinarum and Magnifera Indica. International Journal of Science Technology and Management, 2(1), 42-47.

Kumar, S. N., Aggarwal, P. K., Rani, S., Jain, S., Saxena, R. \& Chauhan, N. (2011b). Impact of Climate Change on Crop Productivity in Western Ghats, Coastal and Northeastern Regions of India (Special Section: Climate Change: Projections and Impact for India). Current Science, 101, 332-341.

Kar, J. \& Kar, M. (2008). Environment and Changing Agricultural Practices: Evidence from Orissa, India. Indus Journal of Management and Social Sciences, 2(2), 119-128.

Kurukulasuriya, P. \& Mendelsohn, R. (2008). A Ricardian Analysis of the Impact of Climate Change on African Cropland. AFJARE, 2(1), 1-23.

Kalra, N., Chakraborty, D., Sharma, A., Rai, J., Monica, H. K., Subhash, C., Kumar, P., Ramesh, B. S., Barman, D., Mittal, R. B., Lal, M. \& Sehgal, M. (2008). Effect of Increasing Temperature on Yield of Some Winter Crops in Northwest India. Current Science, 94(1), 82-88.

Kapur, D., Khosla, R. \& Mehta, P. B. (2009). Climate Change: India's Options. Economic and Political Weekly, 36(31), 34-42.

Mendelsohn, R., Nordhaus, W. D. \& Shaw, D. (1994). The Impact of Global Warming: A Ricardian Analysis. American Economic Review, 84(4), 753-771.

Mano, R. \& Nhemachena, C. (2007). Assessment of the Economic Impacts of Climate Change on Agriculture in Zimbabwe: A Ricardian Approach. Policy Research Working Paper, World Bank. Available at: http://elibrary.worldbank.org/doi/book/10.1596/1813-9450-4292. 
Mongi, H., Majule, A. E. \& Lyimo, J. G. (2010). Vulnerability and Adaption of Rain Fed Agriculture to Climate Change and Variability in Semi-arid Tanzania. African Journal of Environmental Science and Technology, 4(6), 371-381.

Masters, G., Baker, P. \& Flood, J. (2010). Climate Change and Agricultural Commodities. CABI Working Paper, 02.

Nastis, S. A., Michailidis, A. \& Chatzitheodoridis, F. (2012). Climate Change and Agricultural Productivity. African Journal of Agricultural Research, 7(35), 4885-4893.

Nandhini, U. S., Alagumani, T. \& Shibi, S. (2006). Economic Analysis of Agriculture in Southern Parts of Coastal India. Agricultura Tropica et Subtropica, 39(4), 279-284.

Oduol, J. B., Binam, A., Olarinde, J. N. B., Diagne, L. \& Adekunle, A. (2011). Impact of Adoption of Soil and Water Conservation Technologies on Technical Efficiency: Insight from Smallholder Farmers in Sub-Saharan Africa. Journal of Development and Agricultural Economics, 3(14), 655-669.

Onyeji, S. C. \& Fischer, G. (1993). An Economic Analysis of Potential Impacts of Climate Change in Egypt. IIASA Working Paper, 93(12), Laxenburg.

Pandey, A. P. (2007). Indian Sugar Industry -A Strong Industrial Base for Rural India. MPRA Paper, 6065.

Ranuzzi, A. \& Srivastava, R. (2012). Impact of Climate Change on Agriculture and Food Security. ICRIER Policy Series 16.

Ramulu, M. (1996). Supply Response of Sugarcane in Andhra Pradesh. Finance India, 10(1), 116-122.

Saseendran, S. A., Singh, K. K., Rathore, L. S., Singh, S. V. \& Sinha, S. K. (2000). Effects of Climate Change on Rice Production in the Tropical Humid Climate of Kerala, India. Climate Change, 44, 495-514.

Seo, S. N., Mendelshon, R. \& Munasinghe, M. (2005). Climate Change and Agriculture in Sri Lanka: A Ricardian Valuation. Environment and Development Economics, Cambridge University Press, 10(5), 581-596.

Srivastava, A. K. \& Rai, M. K. (2012). Sugarcane Production: Impacts of Climate Change and its Mitigation. Biodiversitas, 13(4), 214-227.

Shrivastava, A. K., Shrivastava, A. K. \& Solomon, S. (2011). Sustaining Sugarcane Productivity under Depleting Water Resources. Current Sciences, 10(06), 748-754.

United Nations Report. (2011). An Assessment of the Economic Impact of Climate Change on the Agriculture Sector in Jamaica. Economic Commission for Latin America and the Caribbean, Subregional Headquarters for the Caribbean.

Zhai, F. \& Zhuang, J. (2009). Agriculture Impact of Climate Change: A General Equilibrium Analysis with Special Reference to Southeast Asia. ADBI Working Paper Series, 131.

\section{APPENDIX}

Table 1: Results for hypothesis testing

\begin{tabular}{|c|c|c|c|}
\hline Applied Test/Model Specification & $\begin{array}{l}\text { Simple Linear } \\
\text { Regression Model }\end{array}$ & $\begin{array}{l}\text { Ricardian } \\
\text { Productivity } \\
\text { Regression model }\end{array}$ & $\begin{array}{l}\text { C-D Production } \\
\text { Function model }\end{array}$ \\
\hline $\begin{array}{l}\text { Breusch-Pagan Lagrange multiplier (LM) test } \\
\text { for random effects [Chibar' }(01)]\end{array}$ & 0.00 & 0.00 & 0.00 \\
\hline $\begin{array}{l}\text { Hausman test for fixed or random effects } \\
{\left[\mathrm{Chi}^{2}(13)\right]}\end{array}$ & $311.20^{*}$ & $171.29 *$ & $131.62^{*}$ \\
\hline $\begin{array}{l}\text { Breusch-Pagan Lagrange multiplier (LM) test } \\
\text { for cross-sectional dependence correlation } \\
{\left[C \text { Ch }^{2}(78)\right]}\end{array}$ & $123.221 *$ & $127.61^{*}$ & $157.20^{*}$ \\
\hline $\begin{array}{l}\text { Pesaran's (CD) test for cross-sectional } \\
\text { dependence correlation }\end{array}$ & $1.781^{* * *}$ & $1.781^{* * *}$ & $2.822^{*}$ \\
\hline $\begin{array}{l}\text { Modified Wald test for heteroskedasticity } \\
{\left[\mathrm{Chi}^{2}(13)\right]}\end{array}$ & $185.55^{*}$ & $119.84^{*}$ & $145.09^{*}$ \\
\hline $\begin{array}{l}\text { Wooldridge test for serial correlation } \\
{[\mathrm{F}(1,12)]}\end{array}$ & $23.869 *$ & $33.756^{*}$ & $40.293^{*}$ \\
\hline
\end{tabular}

Source: Estimated by Authors; and *, ${ }^{* *}$ and ${ }^{* * *}$ indicates the 1\%, 5\% and 10\% significance level. 
Table 2: Regression results for linear model by Prais Winsten models with panels corrected standard errors (PCSEs) estimation

\begin{tabular}{|c|c|c|c|c|c|c|}
\hline \multicolumn{2}{|c|}{$\begin{array}{l}\text { No. of Observation } \\
\text { No. of States } \\
\text { No. of Obs./States }\end{array}$} & \multirow{2}{*}{$\begin{array}{l}390 \\
13 \\
30 \\
\text { Panel } \\
\text { Corr. Std. Errors }\end{array}$} & \multicolumn{2}{|c|}{$\begin{array}{l}\text { R-squared } \\
\text { Wald } \mathrm{Chi}^{2}(15) \\
\text { Prob>Chi' }\end{array}$} & \multicolumn{2}{|l|}{$\begin{array}{l}0.7716 \\
1024.73 \\
0.0000\end{array}$} \\
\hline (tp/as) & $\begin{array}{l}\text { Regression } \\
\text { Coefficient }\end{array}$ & & $\mathbf{z}$ & $\mathbf{P}>|\mathrm{z}|$ & $95 \%$ Conf & ce Interval \\
\hline ia & $0.0479096^{*}$ & 0.008083 & 5.93 & 0.000 & 0.032068 & 0.063752 \\
\hline$T f$ & $-0.1613009^{* *}$ & 0.064294 & -2.51 & 0.012 & -0.28731 & -0.03529 \\
\hline al & $-7.55 e-08$ & $2.69 \mathrm{e}-06$ & -0.03 & 0.978 & $-5.34 e-06$ & $5.19 \mathrm{e}-06$ \\
\hline$T t$ & -0.0001015 & 0.000228 & -0.45 & 0.656 & -0.00055 & 0.000345 \\
\hline$L r$ & $4.752133^{*}$ & 1.177407 & 4.04 & 0.000 & 2.444458 & 7.059809 \\
\hline$f h p$ & $0.0176374^{* *}$ & 0.008033 & 2.20 & 0.028 & 0.001893 & 0.033382 \\
\hline $\operatorname{arfrs}$ & -0.002536 & 0.002618 & -0.97 & 0.333 & -0.00767 & 0.002595 \\
\hline arfws & $0.0099418^{* * *}$ & 0.00522 & 1.90 & 0.057 & -0.00029 & 0.020173 \\
\hline $\operatorname{arfss}$ & 0.0050032 & 0.003272 & 1.53 & 0.126 & -0.00141 & 0.011416 \\
\hline amaxtrs & 8.129719* & 0.817327 & 9.95 & 0.000 & 6.527788 & 9.731649 \\
\hline amaxtws & $1.678273^{* *}$ & 0.806647 & 2.08 & 0.037 & 0.097273 & 3.259273 \\
\hline amaxtrs & $-7.284266^{*}$ & 1.408118 & -5.17 & 0.000 & -10.0441 & -4.52441 \\
\hline amintrs & $-4.09978^{*}$ & 0.522270 & -7.85 & 0.000 & -5.12341 & -3.07615 \\
\hline amintws & $1.812548^{*}$ & 0.631818 & 2.87 & 0.004 & 0.574207 & 3.05089 \\
\hline amintss & $1.375609^{*}$ & 0.377451 & 3.64 & 0.000 & 0.635819 & 2.1154 \\
\hline con. coef. & 36.2764 & 46.64806 & 0.78 & 0.437 & -55.1521 & 127.7049 \\
\hline
\end{tabular}

Source: Estimated by Authors; and ${ }^{*},{ }^{* *}$ and ${ }^{* * *}$ indicates the 1\%, 5\% and 10\% significance level for respective variables.

Table 3: Regression results for Cobb-Douglas production function model by Prais Winsten models with panels corrected standard errors (PCSEs) estimation

\begin{tabular}{|c|c|c|c|c|c|c|}
\hline \multirow{4}{*}{\multicolumn{2}{|c|}{$\begin{array}{l}\text { No. of Observation } \\
\text { No. of States } \\
\text { No. of Obs./States }\end{array}$}} & \multirow{5}{*}{$\begin{array}{l}390 \\
13 \\
30 \\
\text { Panel } \\
\text { Corr. Std. Errors }\end{array}$} & \multirow{4}{*}{\multicolumn{2}{|c|}{ 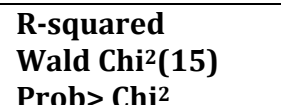 }} & \multirow{4}{*}{\multicolumn{2}{|c|}{$\begin{array}{l}0.6872 \\
809.20 \\
0.0000\end{array}$}} \\
\hline & & & & & & \\
\hline & & & & & & \\
\hline & & & & & & \\
\hline (tp/as) & Regression & & $\mathbf{z}$ & $\mathbf{P}>|\mathbf{z}|$ & \multicolumn{2}{|c|}{$\begin{array}{l}0.0000 \\
95 \% \text { Confidence Interval }\end{array}$} \\
\hline$I a$ & 0.0198025 & 0.021426 & 0.92 & 0.355 & -0.022191 & 0.061796 \\
\hline$T f$ & -0.0329882 & 0.025491 & 1.29 & 0.196 & -0.016972 & 0.082949 \\
\hline$A l$ & $-0.0699627^{*}$ & 0.017592 & -3.98 & 0.000 & -0.104441 & -0.03548 \\
\hline$T t$ & -0.0160224 & 0.018346 & -0.87 & 0.382 & -0.051979 & 0.019935 \\
\hline$L r$ & $0.1410651^{*}$ & 0.039802 & 3.54 & 0.000 & 0.063054 & 0.219075 \\
\hline$f h p$ & $0.0752636^{*}$ & 0.019659 & 3.83 & 0.000 & 0.036733 & 0.113794 \\
\hline arfrs & -0.0264597 & 0.033394 & -0.79 & 0.428 & -0.09191 & 0.038991 \\
\hline arfws & 0.0342118 & 0.015937 & 2.15 & 0.032 & 0.002977 & 0.065447 \\
\hline $\operatorname{arfss}$ & 0.0446389 & 0.036932 & 1.21 & 0.227 & -0.02775 & 0.117024 \\
\hline amaxtrs & $3.59126^{*}$ & 0.779529 & 4.61 & 0.000 & 2.063411 & 5.119109 \\
\hline amaxtws & $2.496673^{*}$ & 0.667123 & 3.74 & 0.000 & 1.189137 & 3.804209 \\
\hline amaxtrs & $-4.494785^{*}$ & 1.11148 & -4.04 & 0.000 & -6.67325 & -2.31632 \\
\hline amintrs & $-0.3841186^{*}$ & 0.094889 & -4.05 & 0.000 & -0.57010 & -0.19814 \\
\hline amintws & -0.0392798 & 0.222088 & -0.18 & 0.860 & -0.47456 & 0.396004 \\
\hline amintss & $0.5075401^{*}$ & 0.181138 & 2.80 & 0.005 & 0.152517 & 0.862563 \\
\hline con. coef. & -0.3297855 & 1.566667 & -0.21 & 0.833 & -3.40040 & 2.740826 \\
\hline
\end{tabular}

Source: Estimated by Authors; and ${ }^{*},{ }^{* *}$ and ${ }^{* * *}$ indicates the 1\%, 5\% and 10\% significance level for respective variables. 
Table 4: Regression results for Ricardian productivity model by Prais Winsten models with panels corrected standard errors (PCSEs) estimation

\begin{tabular}{|c|c|c|c|c|c|c|}
\hline \multicolumn{2}{|c|}{$\begin{array}{l}\text { No. of Observation } \\
\text { No. of States } \\
\text { No. of Obs./States }\end{array}$} & \multirow{2}{*}{$\begin{array}{l}390 \\
13 \\
30 \\
\text { Panel } \\
\text { Corr. Std. Errors }\end{array}$} & \multicolumn{2}{|c|}{$\begin{array}{l}\text { R-squared } \\
\text { Wald Chi' }{ }^{2}(24) \\
\text { Prob> } \text { Chi }^{2}(24)\end{array}$} & \multirow{2}{*}{\multicolumn{2}{|c|}{$\begin{array}{l}0.8379 \\
2196.78 \\
0.0000 \\
95 \% \text { Confidence Interval }\end{array}$}} \\
\hline (TP/AS) & $\begin{array}{l}\text { Regression } \\
\text { Coefficient }\end{array}$ & & $\mathrm{z}$ & $P>|z|$ & & \\
\hline$i a$ & $0.0240739 *$ & 0.00748 & 3.21 & 0.001 & 0.009 & 0.039 \\
\hline$t f$ & $-0.1790186^{*}$ & 0.05431 & -3.30 & 0.001 & -0.285 & -0.073 \\
\hline al & $-7.41 \mathrm{e}-06^{*}$ & $2.01 \mathrm{e}-06$ & 3.69 & 0.000 & $3.48 e-06$ & 0.00001 \\
\hline$t t$ & -0.0000746 & 0.000204 & 0.37 & 0.715 & -0.0003 & 0.0005 \\
\hline$l r$ & $2.310179^{* * *}$ & 1.323545 & 1.75 & 0.081 & -0.284 & 4.904 \\
\hline$f h p$ & $0.0239894^{*}$ & 0.007585 & 3.16 & 0.002 & 0.009 & 0.039 \\
\hline arfrs & 0.0044096 & 0.007997 & 0.55 & 0.581 & -0.011 & 0.0201 \\
\hline $\operatorname{arfrs}^{\wedge 1 / 2}$ & -0.181790 & 0.470289 & -0.39 & 0.699 & -1.103 & 0.739 \\
\hline arfws & $0.032026^{* *}$ & 0.013675 & 2.34 & 0.019 & 0.005 & 0.0588 \\
\hline $\operatorname{arfws} s^{\wedge 1 / 2}$ & $-0.8864564^{* *}$ & 0.378393 & -2.34 & 0.019 & -1.628 & -0.145 \\
\hline $\operatorname{arfss}$ & $-0.0235639 * *$ & 0.009823 & -2.40 & 0.016 & -0.043 & -0.004 \\
\hline $\operatorname{arfss^{\wedge 1/2}}$ & $1.401276^{*}$ & 0.523348 & 2.68 & 0.007 & 0.376 & 2.427 \\
\hline amaxtrs & $133.8864 *$ & 37.68776 & 3.55 & 0.000 & 60.020 & 207.753 \\
\hline $\operatorname{amaxtrs}^{\wedge 1 / 2}$ & $-1452.561^{*}$ & 433.2398 & -3.35 & 0.001 & -2301.695 & -603.426 \\
\hline amaxtws & $118.474^{*}$ & 24.41869 & 4.85 & 0.000 & 70.614 & 166.334 \\
\hline $\operatorname{amaxtws}^{\wedge 1 / 2}$ & $-1248.472^{*}$ & 269.5023 & -4.63 & 0.000 & -1776.687 & -720.257 \\
\hline amaxtss & $119.9152^{* *}$ & 48.89536 & 2.45 & 0.014 & 24.082 & 215.748 \\
\hline 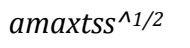 & $-1539.73^{*}$ & 592.8962 & -2.60 & 0.009 & -2701.786 & -377.675 \\
\hline amintrs & -0.738061 & 10.03223 & -0.07 & 0.941 & -20.401 & 18.924 \\
\hline $\operatorname{amintrs}^{\wedge 1 / 2}$ & -11.77637 & 106.0642 & -0.11 & 0.912 & -219.658 & 196.105 \\
\hline amintws & $14.82338^{* *}$ & 5.755262 & 2.58 & 0.010 & 3.543 & 26.103 \\
\hline amintws ${ }^{\wedge 1 / 2}$ & $-101.4968^{* *}$ & 47.51834 & -2.14 & 0.033 & -194.631 & -8.362 \\
\hline amintss & -16.25332 & 15.59702 & -1.04 & 0.297 & -46.822 & 14.316 \\
\hline $\operatorname{amintss}^{\wedge 1 / 2}$ & 175.4554 & 144.979 & 1.21 & 0.226 & -108.698 & 459.609 \\
\hline con. coef. & $11949.32 *$ & 2048.546 & 5.83 & 0.000 & 7934.242 & 15964.39 \\
\hline
\end{tabular}

Source: Estimated by Authors; and ${ }^{*},{ }^{* *}$ and ${ }^{* * *}$ indicates the $1 \%, 5 \%$ and $10 \%$ significance level for respective variables. 